\title{
Wage inequality and unemployment with overeducation
}

\author{
Xavier Cuadras-Morató \\ Universitat Pompeu Fabra \\ Xavier Mateos-Planas* \\ University of Southampton
}

\begin{abstract}
A skill-biased change in technology can account at once for the changes observed in a number of important variables of the US labour market between 1970 and 1990. These include the increasing inequality in wages, both between and within education groups, and the increase in unemployment at all levels of education. In contrast, in previous literature this type of technology shock cannot account for all of these changes. The paper uses a matching model with a segmented labour market, an imperfect correlation between individual ability and education, and a fixed cost of setting up a job. The endogenous increase in overeducation is key to understand the response of unemployment to the technology shock.
\end{abstract}

Key words: unemployment, wage premium, overeducation, SBTC JEL: E24, J31, J64

\section{Introduction}

In the U.S., between 1970 and 1990, unemployment rates for both high-school graduates and college graduates nearly doubled, the wage differential (or premium) between these two education groups widened considerably, and residual wage inequality within the two groups also rose. Table 1 reports figures on the

\footnotetext{
* Corresponding author: Economics Division, School of Social Sciences, University of Southampton, SO17 1BJ United Kingdom; Email fxmp@soton.ac.uk; Phone +44 (0)2380 595669 .
} 
first three variables for the male population in 1970 and $1990 .{ }^{1}$ Juhn et al (1993) and Lemieux (2004), for example, document the typical upward shifts of residual inequality within the high-school and college groups. ${ }^{2}$ The period 1970-1990 is also one where there are clear indications of a rise in the fraction of college graduates that take non-graduate jobs, a phenomenon known as overeducation. Pryor and Schaffer (1997) and Wolff (2000) supply compelling evidence that since 1971 university graduates have increasingly been taking jobs in which the average educational level is much lower. ${ }^{3}$

Table 1. U.S. labour market 1970-1990

\begin{tabular}{|c|c|c|c|}
\hline & college & high-school & \\
\hline year & unemployment rate & unemployment rate & wage premium \\
\hline 1970 & 1.1 & 2.4 & 1.44 \\
\hline 1990 & 2.1 & 5.3 & 1.58 \\
\hline
\end{tabular}

A skill-biased change in technology (hereafter also a SBTC) is commonly regarded as the primary explanation for the widening dispersion of wages. This paper's central point is that the same SBTC which drives wage dispersion also implies a surge in overeducation that helps explain much of the observed changes in unemployment. This contrasts favourably with existing studies where a SBTC cannot account simultaneously for a rise in educated unemployment, a widening in wage dispersion - both across and within education groups - and an upward shift in the degree of overeducation.

This paper pursues two main specific objectives. The first is to present a model of the labour market where overeducation as well as education-specific unemployment and wages are jointly determined. The second objective is to use this model to study, both qualitatively and quantitatively, the ability of a skill-biased change in technology to account for the observed differences in wage inequality and unemployment conditions between 1970 and 1990. Moreover, an interpretation will be sought for the well known observed decline in the college premium during the early sub-period 1970-1980 - a time when college attainment in the labour force was growing very rapidly - which is

1 For unemployment the figures are calculated from the Statistical Abstracts of the US, US Census Bureau (1995), Table 662. The unemployment rates refer to male civilian non-institutional population aged 25-64. The wage premium is the average wage of college white male workers over the average wage for high-school white male workers aged 18-64 as reported in Murphy and Welch (1992) for the years 1969 and 1989 (see also Katz and Murphy (1992) and Card and Di Nardo (2002)).

2 The sustained increase in overall residual inequality during this period has been extensively documented and studied. See, for example, Krusell et al. (2000), Violante (2002), and Heathcote el al. (2004).

3 However Acemoglu (1999), based on PSID survey responses, reports indications of a slight fall in overeducation between 1976 and 1985. 
nonetheless consistent with the SBTC being well underway at that time.

This paper develops a search-matching model of a labour market that is segmented into two education levels. Workers are differentiated by skill (or ability) and education, with these two attributes being only imperfectly correlated. An educated worker has to decide which of the two segments to participate in depending on the employment and wage prospects associated with the two alternatives, whereas a non-educated can only participate in the non-educated segment. Firms decide which education segment to participate in, and which level of skills to hire taking into account a fixed start-up cost and the skill composition of the labour force in the different segments. Workers and firms interact in this economy in an otherwise standard framework with search and matching frictions to determine wages and vacancy/unemployment ratios in the two segments.

This model has three key features. The first is a labour market which is segmented. It presupposes that a worker's education is observable ex-ante and that firms post job vacancies that specify the minimal attainment required on prospective candidates to filling the post. More specifically, vacancies in the 'educated' segment require a degree and vacancies in the 'non-educated' segment do not. Segmentation means that both vacant firms and unemployed workers confine their search efforts to the particular segment they choose, not to both. The second key feature is the assumption that there is an imperfect correlation between skill and education status. That is, the model recognizes that some of the workers in possession of a degree may have a low skill whereas some workers without a degree may have a high skill. Because of the imperfect correlation skill-education, by altering both the skill composition of the labour force participating in the different segments and the distribution of educated workers across segments, endogenous changes in career (or segment) choices may have implications for equilibrium unemployment and wages across education groups. The third remarkable feature of this model is precisely the career decision of educated workers. An educated worker turns to the non-educated segment and thus becomes overeducated when his chances of employment in the educated segment become slim. This can happen to educated yet low skill individuals when, due to the existence of the fixed cost, educated firms refuse to hire them.

The model is analysed to establish some of its basic properties and draw possible implications of a SBTC and changes in the composition of skills in the labour force for the observable variables. Numerical exercises are then conducted to study these effects quantitatively. The benchmark parameters are set to match some long-run observations for the US economy and the 1970 values of key endogenous variables. In the main exercise, the exogenous SBTC shock is measured to match the observed changes in the wage premium between 1970 and 1990. In another exercise, the SBTC shock is accompanied 
by a decline in the skill composition of the educated labour force. These two sets of shocks are then used to produce steady-state equilibrium outcomes for the entire range of labour market variables of interest which are to be compared, respectively, with the 1970-1990 and 1970-1980 facts reported above. In order to gain further quantitative insight, a shock to the general employment conditions in the form of a shift in matching technology will also be considered. ${ }^{4}$

The findings are as follows. A SBTC may lead to a situation where firms looking for educated workers will not find it profitable to hire low-productivity individuals who will, consequently, turn to seek employment in the segment of firms that do not require qualified workers. This overeducation then causes higher unemployment within the educated group since the fraction of overeducated workers are subject to the tougher high-unemployment conditions of the non-educated segment. This can also be consistent with a higher unemployment rate for the non-educated workers and widening wage dispersion across and within education groups. The quantitative exercises demonstrate that the SBTC can account for most of the changes in the wage premium and the educated unemployment rate between 1970 and 1990, and about sixty percent of the rise in the non-educated unemployment rate. Moreover, this is also qualitatively in accord with the observed upward shift in overeducation and residual inequality. The introduction of tougher employment (or matching) conditions alongside the SBTC is enough to get a close match to the data. As for the fall in the wage premium during the earlier subperiod 1970-1980, a SBTC still remains a very plausible explanation for the rising unemployment rates if accompanied by a empirically defensible temporary decline in the proportion of skilled workers within the educated group. The marked growth in the numbers of college graduates and the direct evidence on ability scores lend support to this hypothesis. This stands in contrast with the more common explanations based on a deterioration of the general employment conditions.

A previous paper Cuadras-Morató and Mateos-Planas (2006) also studies some of the 1970-1990 labour market central facts with a model that shares many features with the present paper. There are nonetheless a number of notable differences. First, in that paper the absence of a start-up cost rules out overeducation and, therefore, a shock to the employment conditions, in addition to a SBTC, is indispensable to explain a rise in the educated unemployment rate. In the present paper, the SBTC causes most of the observed changes in all the variables because of the response of overeducation. Second, that previous paper endogeneizes the distribution of skills and education in the labour force through the individual choices on education. These changes, while playing a central role for the wage premium and unemployment rates, have counter-

$\overline{4}$ Blanchard and Diamond (1989) and Bleakey and Furhrer (1997) discuss the empirical relevance of changes in the efficiency of the matching process. 
factual implications for residual inequality. The simpler explanation of the present paper, resting mostly on a SBTC, does not require specific changes in the composition of the labour force and is consistent with rising residual inequality.

A number of papers have also studied the implications of a SBTC for dimensions of wage inequality and unemployment in a search-matching setup. The literature includes Mortensen and Pissarides (1999), Acemoglu (1999), Albrecht and Vroman (2002), Shi (2002), Wong (2003), and Moore and Rajan (2005). The differences in results and approach between the present and these paper can be outlined as follows. Regarding the results, in the present paper a SBTC causes rises in unemployment rates and residual inequality within the two education groups, a higher wage premium, and a higher degree of overeducation. In these other papers, a SBTC fails in at least two of these dimensions. Morten and Pissarides (1999) cannot explain rising skilled unemployment and, by design, says nothing about overeducation or residual inequality within education groups. Acemoglu (1999) fails to explain rising residual inequality in any group and Albrecht and Vronan (2002) fails in the unskilled group. Both papers imply a reduction of overeducation (or mismatch) rather than an increase. In the present paper, the reduction in mismatch is associated with higher overeducation instead. In Shi (2002) residual inequality among the skilled remains constant at zero and the unemployment rate of the educated declines. In Wong (2003) residual inequality and the unemployment rate both decline. In Moore and Rajan (2005) wage inequality increases but unemployment falls for the skilled and, under some conditions, for the unskilled too. On the other hand, only Mortensen and Pissarides (1999), and Wong (2003) share with the present paper a quantitative approach to evaluating the implications of the theory. ${ }^{5}$

These contrasting results between the present and the other papers cited can be traced down to basic characteristics of the formal analysis. First, in the current paper the assumed imperfect correlation between education and skill has an important role. The previous papers treat education as equivalent to skill instead. Second, and related to the previous point, the present model assumes that the labour market is segmented in terms of jobs with different observable education requirements rather than skill requirements. Technically, there is a matching function for each segment. ${ }^{6}$ However firms in the two segments have the same production technology. The assumption in Mortensen and Pissarides (1999) is similar but, there, each different segment is perfectly associated with

$\overline{5}$ In Acemoglu (1999), there are no initial differences in unemployment between education categories; in Albrecht and Vroman (2002) there is residual inequality only among the skilled; in Shi (2002) there is residual inequality only among the unskilled.

6 This is also a feature of Saint-Paul (1996) and Moore and Rajan (2005). 
each of the (many) observable productivity-skill levels. In Acemoglu (1999) there is no segmentation in the sense of the present paper, so education is not used to sort applicants into job categories through differentiated matching processes. ${ }^{7}$ This is also true of Albrecht and Vroman (2002), and Wong (2003) where there are however two types of firms with different technologies of production. Two types of firms are also assumed in Shi (2002) but that is a model of directed search where the endogenous matching process leads to a segmentation similar to that in the present paper. Third, in the present paper a SBTC effects a shift in the segment choice by educated workers with different skill characteristics which brings about key changes in the skill composition of the labour force. The stories in Acemoglu (1999), Albrecht and Vroman (2002) and Wong (2003) rest also on a shift in the pairing of workers' skills and firms' types but these cannot have implications for the makeup of the labour supply.

The rest of the paper is organized as follows. Section 2 presents the model and basic behavior relations. Section 3 characterizes the equilibrium. Section 4 discusses qualitatively some key comparative statics. Section 5 presents the baseline calibration. Section 6 reports the results of the numerical analysis. Section 7 concludes the paper with final remarks.

\section{Model}

The model is closely related to the one proposed in Cuadras-Morató and Mateos-Planas (2006) and for some details and derivations the reader will be referred to that paper. Agents in the model consist of workers and firms. A worker's type is defined by two characteristics: skill (indexed by $j$ ) and education (indexed by $i)$. A worker can be skilled $(j=s)$ or non-skilled $(j=n s)$, and educated $(i=e)$ or non-educated $(i=n e)$. Active workers can be employed or unemployed and searching for a job. Firms can be either posting one job vacancy and searching or producing output with one worker. Workers and firms that are searching meet through a matching process. Firms observe the education status of a worker at any time but only observe her skill level after being matched. It is assumed that a posted vacancy must be directed to workers of a specific education group (further details below). More specifically, a firm can be of one of two types, educated or non-educated $i \in\{e, n e\}$,

\footnotetext{
7 Therefore, in the equilibria studied in the present paper all firms within any of the two segments will be of the same type. This rules out situations with two types of firms catering for workers with different skill level in the same segment, which is precisely the type of situation that corresponds to a separating equilibrium in Acemoglu (1999)'s model of a single-segment market. The present paper assumes instead two segments and only considers pooling equilibria within each segment.
} 
according to whether it targets educated workers or not. This implies that the labour market is segmented by education requirements, with a matching process taking place in each segment separately. The rest of this section describes in detail the model and the decision problems faced by workers and firms, and characterizes the optimal choices. Attention is restricted to stationary situations with constant decision rules.

\subsection{Workers}

Workers in the labour force are distributed over the four types according to a distribution whereby $\mu(j, i)$ denotes the fraction of workers with skill level $j \in\{s, n s\}$ and education $i \in\{e, n e\}$. Workers face a constant probability of leaving the labour force, $\rho$. When a worker leaves, another worker of exactly the same type replaces her. This distribution is exogenous. ${ }^{8}$

The timing of events for a worker is as follows. First, the worker enters the labour force and decides which segment (or career) of the market, $i \in\{e, n e\}$, to participate in. A non-educated worker only searches for jobs in the noneducated segment. This follows because, as described below in section 2.2, firms posting vacancies in the educated segment will consider contacts only with workers holding proof of education. Educated workers can instead search in either segment. Let $\phi_{j} \in\{0,1\}$ represent the decision of an educated worker with skill $j$ whether to participate (value 1 ) or not in the educated segment, so $1-\phi_{j}$ is her decision to participate in the non-educated segment. Figure 1 is introduced to visualize the type of configurations that may arise.

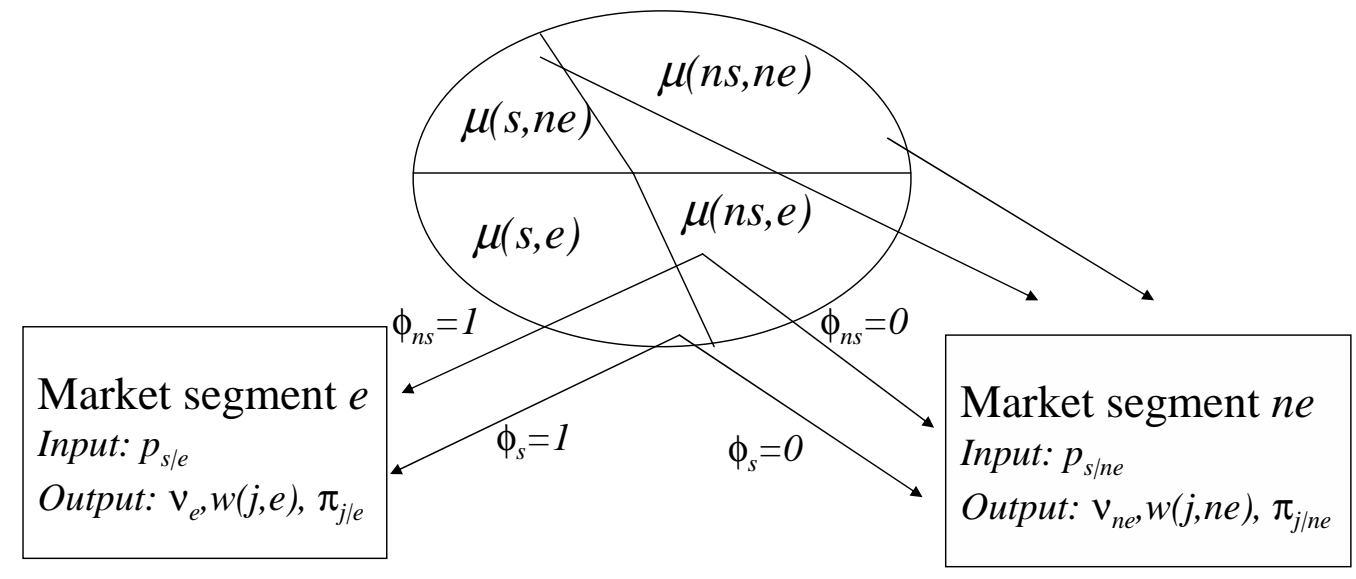

Figure 1. The allocation of workers to segments.

The circle represents the composition of the total labour force in terms of workers' types. The size of the different slices thus corresponds to the postu-

$\overline{8}$ In Cuadras-Morató and Mateos-Planas (2006) it is an endogenous variable. 
lated distributed distribution of skills $\mu(j, i)$. The bottom and top sections on the circle account for the skill composition of the educated and non-educated groups of population respectively. Education and skill are imperfectly correlated when $\mu(s, n e)$ and/or $\mu(n s, e)$ are positive. The boxes represent the two market segments and the arrows show the possible assignments of the labour force of different types to the market segments. The career decision, $\phi_{j}$, determines the direction of this flow for the educated workers in the two bottom sections of the circle. Thus the given distribution of the labour force over skill and education status (the slices in the circle) and the career decisions (the arrows) will jointly determine the skill composition of the labour force that participates in each segment, $p_{j \mid i}$ : the proportion of workers in segment $i \in\{e, n e\}$ with skill $j \in\{s, n s\}$. The skill composition of the educated population $\mu(j, e) /(\mu(s, e)+\mu(n s, e))$ (i.e., the relative size of the two bottom slices of the circle) and the skill composition of the educated segment $p_{j \mid e}$ will coincide if $\phi_{s}=\phi_{n s}=1$. In effect, an explicit expression for the distribution of skills within each segment can be written as follows:

$$
\begin{aligned}
p_{s \mid e} & =\frac{\phi_{s} \mu(s, e)}{\phi_{s} \mu(s, e)+\phi_{n s} \mu(n s, e)} \\
p_{s \mid n e} & =\frac{\mu(s, n e)+\left(1-\phi_{s}\right) \mu(s, e)}{\mu(s, n e)+\mu(n s, n e)+\left(1-\phi_{n s}\right) \mu(n s, e)}
\end{aligned}
$$

Second, the worker starts searching for a job. Workers and firms are matched randomly. The probability that a worker searching in segment $i$ makes contact with a suitable firm is $\nu_{i}$. The value of being unemployed and searching to a worker with skill $j$ and seeking employment in segment $i$ is denoted by $U(j, i)$. In a steady-state one can argue that the Bellman values are not indexed by the worker's education type since the worker, even if educated, will never want to exercise the option to switch segment at a later date. Third, upon contact with a firm the skill of the worker $j$ is disclosed. The unemployed worker must agree with the vacant firm on whether to create the job or continue searching. The decision of the firm whether to hire the worker is denoted by the indicator $\pi_{j \mid i} \in\{0,1\}$, with value 1 if the decision is positive. If the job is created, the wage to the worker is $w(j, i)$ and the value of the match is $W(j, i)$. The job is terminated exogeneously with a Poisson probability $\lambda$. In this event, the agent becomes unemployed and searches for a new job. There is a flow value to the unemployed worker that depends on the wage:

$$
b(w(j, i))=b_{0}+b_{1} w(j, i)
$$

The coefficient on the wage can be interpreted as the unemployment benefit replacement rate. The fixed component may include the value of leisure.

The worker seeks to maximize the expected present value of utility and dis- 
counts the future at the constant rate $r$. The instantaneous utility is given by the value of consumption. Free borrowing and lending is assumed so that in equilibrium the interest rate equals $r$ and hence the worker maximizes the present value of wages plus unemployment compensation. With the notation introduced, the Bellman equation for the value of a job to a worker with skill $j$ and matched with a firm in segment $i$ is

$$
(r+\rho) W(j, i)=w(j, i)+\lambda(U(j, i)-W(j, i)) .
$$

The value of unemployment for a worker with skill $j$ in segment $i$ is

$$
(r+\rho) U(j, i)=b(w(j, i))+\nu_{i} \pi_{j \mid i} \max \{W(j, i)-U(j, i), 0\}
$$

for $i=e, n e$ and $j=s, n s$. Concerning career (or segment) choices, for a noneducated worker the only segment available is $i=n e$. The choice of segment by an educated worker with skill $j$ can be represented by

$$
\phi_{j}=\left\{\begin{array}{l}
1 U(j, e)-U(j, n e)>0 \\
0 \text { otherwise }
\end{array}\right.
$$

Returning to Figure 1, one can now outline the interactions that in the complete model will be key to understand the determination of the variables object of this paper: education-specific unemployment rates and wages, and residual wage inequality. The boxes show that, once the skill composition of the labour force in a particular segment $i, p_{j \mid i}$, has been determined, the hiring policy of firms $\pi_{j \mid i}$, the wage structure $w(j, i)$, and the probability of contact for an unemployed worker $\nu_{i}$ will all be fully determined within the segment. The direct implications of these segment-specific variables for the wages and unemployment rates across and within education groups will depend on the skill and career composition of these groups. Shifts in career and hiring choices have in turn two types of implications for education-specific wages and unemployment rates. The first comes from altering the $p_{j \mid i}$ 's and thereby the segment-specific outputs as just described. The second is a composition effect due to the changes in the relative proportion of agents with different skill and career within each education group for given segment-specific outputs.

\subsection{Firms}

The timing of events is as follows. First, an inactive firm creates a job vacancy that specifies the education requirement on the worker sought, $i$, or the market segment. When making this choice, it is assumed that a firm in the educated 
segment commits to hire only educated workers. ${ }^{9}$ The value of such a vacancy is $V(i)$. A vacancy is posted and there is contact with a suitable job seeker with probability $\xi_{i}$. The skill status, $j$, of the worker met in segment $i$ is not observed by the firm at this stage. The firm holds instead a rational belief about the probability that a matched worker in that segment has skill of type $j$. This coincides with the equilibrium fraction of workers with skill $j$ within the pool of unemployed workers participating in the market segment $i, z_{j \mid i}$. Posting a vacancy has a flow recruiting $\operatorname{cost} c_{R}$.

Second, upon contact, the firm observes the worker's skill, and the firm and the worker agree on whether to create the job. As before, $\pi_{j \mid i} \in\{0,1\}$ denotes the decision by the firm of type $i$ whether to hire a worker with skill $j$. When the job is created, the firm has to pay a fixed cost of $c_{k}$ units associated with the training of the worker and/or administrative regulations. ${ }^{10}$

Third, the firm starts operating and the flow of output it receives is $y(j, i)$. The value of the existing job match for the firm is $J(j, i)$. The match terminates as the consequence of an exogeneous job failure which occurs with Poisson probability $\lambda$. The job can also break down by the worker leaving the labour force which occurs at rate $\rho$. When the job is terminated, the firm will seek to open a new vacancy type $i$ of the highest value. Like the worker, the firm discounts future values at the constant interest rate $r$. Formally, the value of a job of type $(j, i)$ obeys the Bellman equation

$$
r J(j, i)=y(j, i)+(\lambda+\rho)\left[\max _{i^{\prime} \in\{e, n e\}} V\left(i^{\prime}\right)-J(j, i)\right]
$$

and the value of a vacancy of type $i$ satisfies

$$
\begin{aligned}
r V(i) & =-c_{R}+\xi_{i} \sum_{j=s, n s} z_{j \mid i} \pi_{j \mid i}\left[J(j, i)-V(i)-c_{k}\right] \\
\pi_{j \mid i} & =\left\{\begin{array}{l}
0 J(j, i)-V(i)-c_{k} \leq 0 \\
1 J(j, i)-V(i)-c_{k}>0
\end{array}\right.
\end{aligned}
$$

\subsection{Technology}

The flow of output to a match depends on the worker's productivity. Let $\eta_{j}$ denote the productivity of a worker with skill $j$ and assume that $\eta_{s}>\eta_{n s}$. The output of a match involving a worker with skill $j$ equals the value of the

\footnotetext{
$\overline{9}$ See Cuadras-Morató and Mateos-Planas (2006) for some justification of this assumption.

${ }^{10}$ Cuadras-Morató and Mateos-Planas (2006) assume $c_{k}=0$.
} 
gross income flows

$$
\eta_{j}=w(j, i)+y(j, i) .
$$

There is a homogenous-of-degree-one matching function that gives the number of matches per period in segment $i, m_{i}=m\left(v_{i}, u_{i}\right)$, where $v_{i}$ is the mass of vacant firms and $u_{i}$ is the number of unemployed workers in this segment. This matching technology is specified as:

$$
m(v, u)=m_{0} v^{1-\theta} u^{\theta}, \quad \theta \in[0,1],
$$

and $m_{0}>0$ characterizes the efficiency of the matching process. Then the probabilities of contact that are relevant to firms and workers are

$$
\begin{aligned}
& \xi_{i}=m_{i} / v_{i}=\xi\left(v_{i} / u_{i}\right)=m_{0}\left(\frac{v_{i}}{u_{i}}\right)^{-\theta} \\
& \nu_{i}=m_{i} / u_{i}=\nu\left(v_{i} / u_{i}\right)=m_{0}\left(\frac{v_{i}}{u_{i}}\right)^{1-\theta}
\end{aligned}
$$

so $\xi^{\prime}()<$.0 and $\nu^{\prime}()>$.0 .

\subsection{Bargaining, free-entry, and skills of the unemployed}

The wage is determined at each instant of time through bargaining over the surplus of a match between the firm and the worker that have agreed to create a job. The solution to the corresponding generalized Nash bargaining problem is

$$
w(j, i)=\arg \max \left\{\beta \log S_{W}(j, i)+(1-\beta) \log S_{F}(j, i)\right\},
$$

where $S_{W}$ and $S_{F}$ represent the match surplus to the worker and the firm respectively, and $\beta$ represents the workers' bargaining power. For the worker $S_{W}(j, i) \equiv W(j, i)-U(j, i)$. For the firm, $S_{F}(j, i) \equiv J(j, i)-V(i)$. Using Eq.(2)-(4) and (6)-(7), the necessary first-order condition for this problem is:

$$
\frac{1-\beta}{\beta\left(1-b_{1}\right)}(W(j, i)-U(j, i))=J(j, i)-V(i)
$$

There is free-entry in vacancies which leads to the exhaustion of pure rents from vacancy creation in both segments $i \in\{e, n e\}$ :

$$
V(i)=0
$$

The firms in a segment $i$ take as given the skill composition of the pool of unemployed workers from which matches are drawn, $z_{j \mid i}$. This depends of the skill-composition of the labour force in this segment, $p_{j \mid i}$, and the forces deter- 
mining unemployment, including matching and hiring rates, $\nu_{i}$ and $\pi_{j \mid i}$. Supposing that workers are always willing to accept the job offers made by firms, then in a steady-state the equalization of the flows in and out of employment will lead to the following expression (see Cuadras-Morató and Mateos-Planas 2006):

$$
z_{s \mid i}=1-z_{n s \mid i}=p_{s \mid i}\left(\frac{\nu_{i} \pi_{s \mid i}+\lambda+\rho}{\nu_{i} \pi_{n s \mid i}+\lambda+\rho}\left(1-p_{s \mid i}\right)+p_{s \mid i}\right)^{-1}
$$

\section{Equilibrium}

An equilibrium is a situation consistent with Eq. (1)-(11) above and, then, also Eq.(12) since workers always accept a job offer. ${ }^{11}$ A more useful definition follows.

Definition. Consider as given $\lambda, \beta, r, \rho, \theta, \mu(j, i), m_{0}, c_{k}, \eta_{s}, \eta_{n s}, \alpha, b_{0}, b_{1}$, and $c_{R}$. An equilibrium consists of values $v_{i} / u_{i}, w(j, i), \pi_{j \mid i}$, and $p_{j \mid i}$, and $\phi_{j}$, for $i=e, n e$ and $j=s, n s$ such that:

(i) Given $p_{j \mid i}$, the values $v_{i} / u_{i}, w(j, i)$ and $\pi_{j \mid i}$ satisfy Eq.(3),(4),(6),(7), (9)(12).

(ii) Given $v_{i} / u_{i}, w(j, i)$, and $\pi_{j \mid i}$ for $i=e, n e$, the conditions in Eq.(5) determine $\phi_{j}$ for $j=s, n s$, with the value functions in Eq.(5) satisfying Eq.(3),(4),(6),(7), (8)-(12).

(iii) The values $p_{s \mid i}$ are determined from $\phi_{j}$ according to Eq.(1).

(iv) $p_{s \mid e}>p_{s \mid n e}$.

In point $(i)$ the equilibrium can be analysed first for the case that the skill composition of the labour force in the two segments $p_{s \mid i}$ 's are given. Conditions (ii) - (iii) concern the determination of this composition $p_{s \mid i}$ through the career choices $\phi_{j}$ 's. The last point $(i v)$ is a restriction on the type of outcomes that are of interest, and will be discussed further in section 3.2 below. Before dealing with the interactions between career choices and the labour market outcomes, this section begins with the case that the career decisions are exogenous.

\subsection{Exogenous career choices}

This section studies first the equilibrium in each segment when the career choices $\phi_{j}$ 's are exogenous (i.e., only point $(i)$ of the definition needs to be

11 The decision of a worker whether to accept an offer in Eq.(4) is dominated by the hiring decision of the firm $\pi_{j \mid i}$ in Eq.(7b) since Eq.(10) must hold. 
satisfied), which implies that the distribution of skills (i.e., the $p_{j \mid i}$ 's) is given too. Then an equilibrium determines the variables $v_{i} / u_{i}$ (or, by Eq. $(9), \nu_{i}$ ), $w(j, i)$, and $\pi_{j \mid i}$ for $i=e, n e$ and $j=s, n s$. These are the outputs inside the boxes in Figure 1. They can be characterized by a couple of relationships.

One type of relation comes from developing the bargaining condition Eq.(10). This is a version of the job-destruction curve in Mortensen and Pissarides (1994) which gives the wage as a function of the worker's skill, the segment's tightness and the firm's hiring decisions. It reads as follows:

$$
w(j, i)=\frac{\left(\eta_{j}-b_{0}-b_{1} \eta_{j}\right)}{1-b_{1}} \frac{\beta \nu\left(v_{i} / u_{i}\right) \pi_{j \mid i}+\beta(r+\rho+\lambda)}{\beta \nu\left(v_{i} / u_{i}\right) \pi_{j \mid i}+(r+\rho+\lambda)}+\frac{b_{0}}{1-b_{1}}
$$

Eq.(13) traces out a positive relation between the wage and the equilibrium market tightness - provided that the minimal condition $\eta_{j}\left(1-b_{1}\right)-b_{0}>$ 0 holds. The interpretation is as follows. A higher probability of meeting a vacancy for the worker, $\nu_{i}$, means that the outside option of a job is also higher. Hence the wage has to be also higher to keep the worker into the job. Since $\nu_{i}$ depends positively of market tightness, the positive relation between $v_{i} / u_{i}$ and $w(j, i)$ follows. In Figure 2, the two upward-sloping curves denoted $J D(s, i)$ and $J D(n s, i)$ represent the two job-destruction relations described by Eq.(13), one for each skill level $j$.

The other type of relation comes from developing the free-entry condition Eq.(11). This delivers the following:

$$
\begin{gathered}
\xi\left(v_{i} / u_{i}\right) \sum_{j=s, n s} z_{j \mid i} \pi_{j \mid i}\left[\frac{1}{r+\lambda+\rho}\left(\eta_{j}-w(j, i)\right)-c_{k}\right]-c_{R}=0 \\
\pi_{j \mid i}=\left\{\begin{array}{l}
0\left[\frac{1}{r+\lambda+\rho}\left(\eta_{j}-w(j, i)\right)-c_{k}\right]<0 \\
1 \text { otherwise }
\end{array}\right.
\end{gathered}
$$

where the firm's net profit is in brackets and, using Eq.(12) with (9),

$$
z_{s \mid i}=1-z_{n s \mid i}=p_{s \mid i}\left(\frac{\nu\left(v_{i} / u_{i}\right) \pi_{s \mid i}+\lambda+\rho}{\nu\left(v_{i} / u_{i}\right) \pi_{n s \mid i}+\lambda+\rho}\left(1-p_{s \mid i}\right)+p_{s \mid i}\right)^{-1}
$$

This expression is associated with the idea of job creation. A higher probability of contacting a worker for the firm, $\xi_{i}$, increases the expected profits for a given allocation of output between the worker and the firm. Then free-entry would drive the wages upwards so as to restore the zero value of creating vacancies. Since $\xi_{i}$ depends negatively on market tightness, a negative relation between $v_{i} / u_{i}$ and wages follows for each $j=s, n s$. In Figure 2, the two downward-sloping curves denoted $J C$ are associated with the job-creation re- 
lation implied by Eq.(14), one for each skill level. More specifically, for a given tightness $v_{i} / u_{i}$, the corresponding point on $J C\left(s, i \mid w^{e q}(n s, i)\right)$ represents the skilled wage that satisfies Eq.(14) for the given equilibrium non-skilled wage $w^{e q}(n s, i)$. Points on the other curve $J C\left(n s, i \mid w^{e q}(s, i)\right)$ represent the non-skilled wage consistent with Eq.(14) given the equilibrium skilled wage $w^{e q}(s, i)$. Note that any of the two curves exists only as long as the firms in the segment are willing to hire the worker of the corresponding skill level $j$ (i.e., $\pi_{j \mid i}=1$ ) and that if instead $\pi_{j \mid i}=0$ then $J C(j, i)$ cannot be drawn.

For each segment $i$, the equilibrium can then be expressed as a market tightness $v_{i} / u_{i}$ and a pair of wages $w(s, i)$ and $w(n s, i)$ that satisfy Eq.(13) and (14). Graphically, in Figure 2 the equilibrium is characterized by the single market tightness and the two wages where the pairs of curves $J C$ and $J D$ associated with each skill level intersect, and the wages so determined match the equilibrium values underlying the two $J C$ curves. ${ }^{12}$

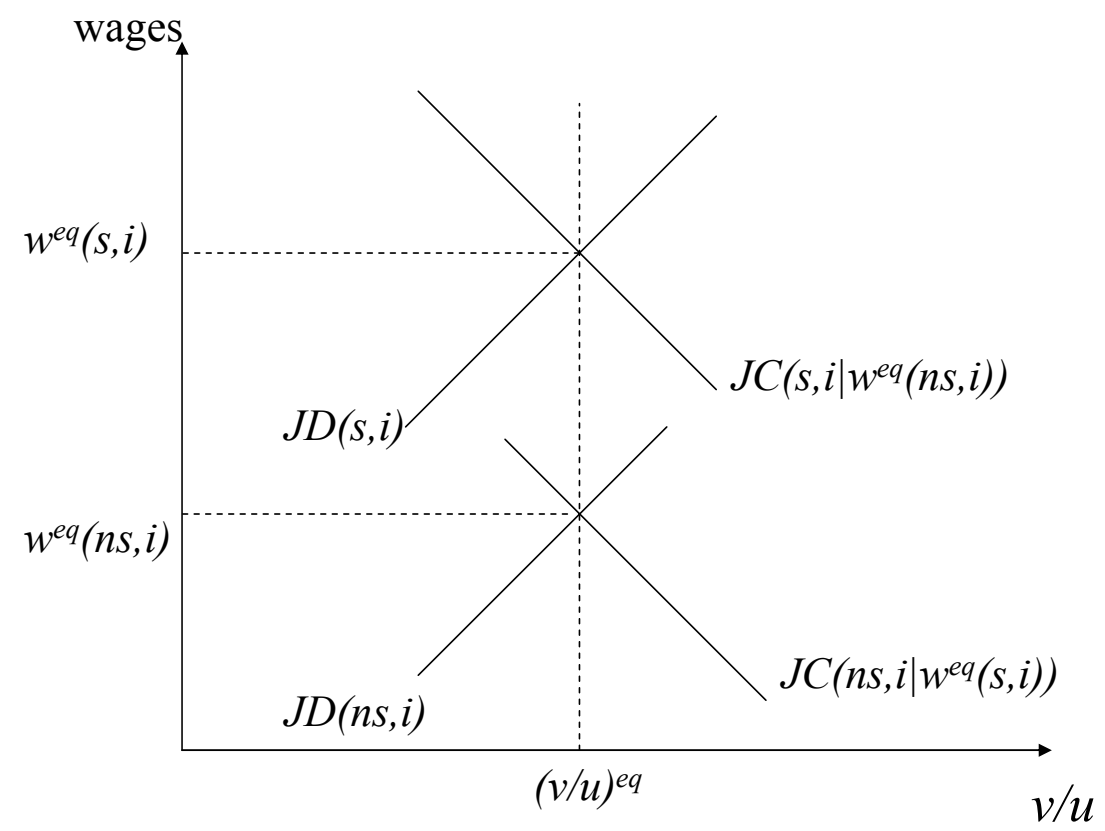

Figure 2. Equilibrium in segment $i$.

This representation of the equilibrium as the solution to the system Eq.(13)(14) will prove useful to articulate the discussion of comparative statics later on. However, in order to establish fundamental results on existence, multiplicity, and properties of the equilibria a more manageable version will prove

\footnotetext{
$\overline{12}$ If for example the $n s$ workers are not hired and $\pi_{n s \mid i}=0$, then the equilibrium if fully characterized by the intersection between $J D(s, i)$ and $J C(s, i)$ where the latter does not depend on $w(n s, i)$. This notional wage $w(n s, i)$ is still given by the point on $J D(n s, i)$.
} 
useful. It can be derived by writing Eq.(13) as

$$
\eta_{j}-w(j, i)=\frac{(r+\rho+\lambda)(1-\beta)\left[\left(1-b_{1}\right) \eta_{j}-b_{0}\right]}{\left(1-b_{1}\right)\left(r+\rho+\lambda+\beta \nu\left(v_{i} / u_{i}\right) \pi_{j \mid i}\right)}
$$

which can be used to replace the terms $\eta_{j}-w(j, i)$ in Eq.(14). This delivers a single equation in market tightness whose solution is an equilibrium. The equilibrium in segment $i$ can then be expressed as a market tightness $v_{i} / u_{i}$ that satisfies Eq.(14) with Eq.(15). It must therefore be consistent with the firm's hiring policy $\pi_{j \mid i}$ in Eq.(14b) which characterizes the choice of the firm whether to create the job when contacting an unemployed worker with skill $j$. There is the possibility that a match with a particular skill $j$ is not profitable and the job is not created, but observe that Eq.(14a) requires that at least for one $j$ the job is created. Changes in career decision enter this condition through changes in the composition of the labour force $p_{s \mid i}$ and thus the probabilities that, say, an unemployed worker is skilled in the educated segment, $z_{s \mid e}$, in Eq.(14c). Since the educated and the non-educated sectors are both operative, any firm must be willing to hire at least the skilled workers so that one can set $\pi_{s \mid e}=\pi_{s \mid n e}=1$. In principle, the non-skilled workers may be hired in either sector, both sectors or none sector.

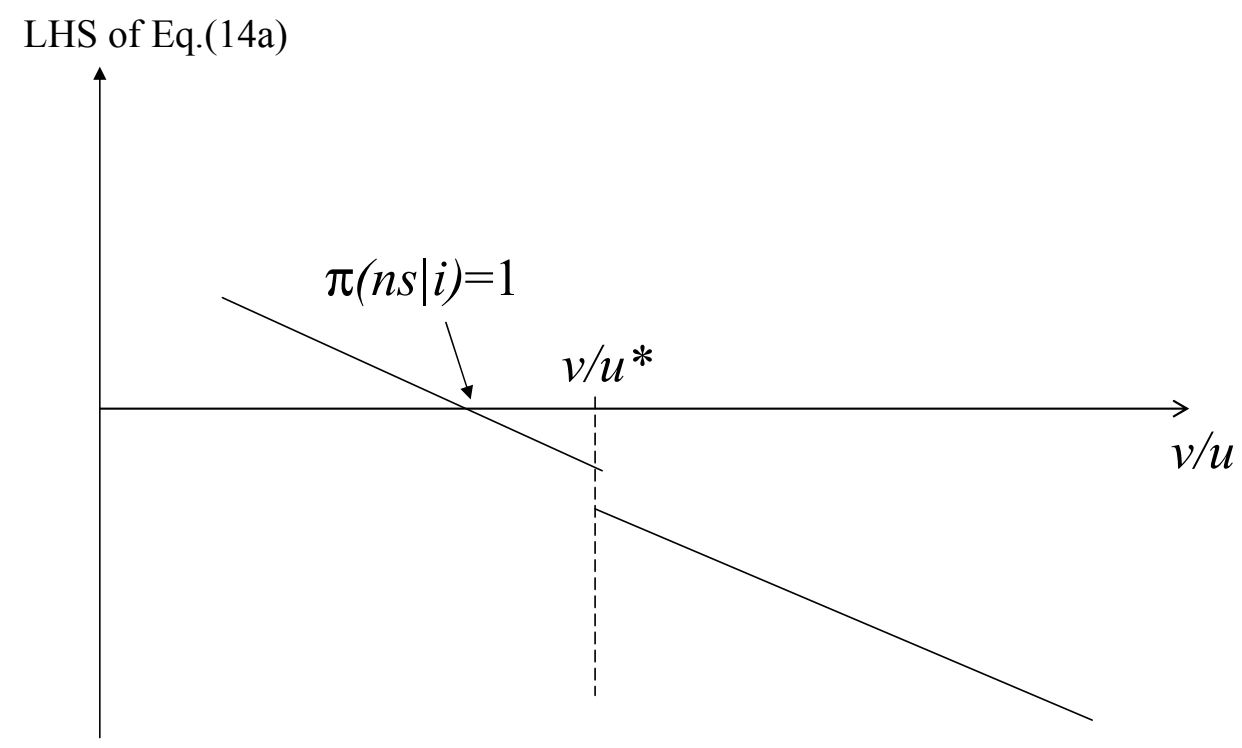

Figure 3. Equilibrium in segment $i$.

In order to make this characterization more precise Figure 3 is introduced. It represents the left-hand side of Eq.(14a) as a decreasing function of $v_{i} / u_{i}$, on account of Eq.(14b)-(14c) and Eq.(15). Thus an equilibrium must be unique. Also existence requires that the curve lies above the horizontal zero line for low values of the market tightness. Formally, given the limiting properties of the function $\xi($.$) , a necessary condition for existence is that firms be willing$ 
to hire at least skilled workers when tightness is very low.

The left-hand side of Eq.(14a) has a discontinuity at the value $\left(v_{i} / u_{i}\right)^{*}$ of market tightness where, according to Eq.(14b), $\pi_{n s \mid i}$ shifts from 1 to 0 or, in other words, the value at which it is no longer profitable for firms in segment $i$ to hire non-skilled workers. At this point, the probability of meeting a skilled worker among the pool of unemployed, $z_{s \mid i}$ in Eq.(14c), drops because all the non-skilled workers in this segment become unemployed. An equilibrium may not exist due to this discontinuity. When there is a zero of the LHS of Eq.(14a) to the right of $\left(v_{i} / u_{i}\right)^{*}$, non-skilled workers are not hired, otherwise both skill types are hired. Figure 3 has been drawn for the latter case so $\pi_{n s \mid i}=1 .{ }^{13}$ A proposition in Cuadras-Morató and Mateos-Planas (2006) summarizes this discussion more formally.

\subsection{Endogenous career choices}

The skill composition $p_{s \mid i}$ has been taken as given so far. In equilibrium, it must be consistent with points $(i i)-(i v)$ of the definition of equilibrium. That is to say, it must be true that there is a more skilled labour force in the educated segment $p_{s \mid e}>p_{s \mid n e}$, and that the $p_{j \mid i}$ 's are determined by the career decisions of workers according to Eq.(1) and (5), with the equilibrium values of searching in alternative segments satisfying

$$
(r+\rho) U(j, i)=b(w(j, i))+\nu\left(v_{i} / u_{i}\right) \pi_{j \mid i} \frac{w(j, i)-b(w(j, i))}{r+\rho+\lambda+\nu\left(v_{i} / u_{i}\right) \pi_{j \mid i}},
$$

where the equality follows from Eq.(3) and (4).

The last point $i v$ implies that $\phi_{s}=1$ and that the key interesting career decision is $\phi_{n s}$. The analysis will be restricted to equilibrium situations where both the educated and the non-educated labour-market segments are operative, and where the proportion of skilled workers is higher among the labour force that participates in the educated segment (i.e., $p_{s \mid e}>p_{s \mid n e}$ ). The latter is intuitive and convenient since it restricts the type of career choices that may arise in equilibrium. In effect, the skilled workers that are educated must decide to participate in the educated segment, or $\phi_{s}=1$. Otherwise, existence of an active educated segment would require the non-skilled educated workers to be the only participants in the educated segment (see again Figure 1). But then non-skilled agents would be most numerous in the educated segment, which is inconsistent with the required condition on the $p_{j \mid i}$ 's. That $\phi_{s}=1$ will in turn imply, by Eq.(5) with (16) and (13), that in equilibrium market tightness is higher in the educated segment.

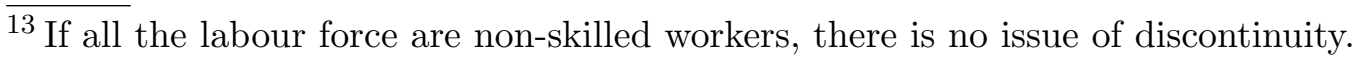


Proposition 1.In an equilibrium workers who are educated and skilled must participate in the educated segment, or $\phi_{s}=1$, and market tightness is higher in that segment, or $v_{e} / u_{e}>v_{n e} / u_{n e}$.

Thus variation in labour-force participation (or career) will occur only through the choice by the educated non-skilled workers, $\phi_{n s}$. An unsurprising yet important result is that educated non-skilled workers will turn to the noneducated segments when they see no chance of employment in the educated segment. ${ }^{14}$ The reverse implication that educated individuals will leave the educated segment only if firms there do not hire them is also true. Proposition 2 states this more precisely.

Proposition 2. Suppose that $\pi_{n s \mid n e}=1$. Then $\pi_{n s \mid e}=0$ if and only if $\phi_{n s}=0$.

Proof: If $\pi_{j \mid i}=1$ then Eq. (7b) and (10) imply that $W(j, i)-U(j, i)>0$. Using this in Eq. (3) and (4) shows that if $\pi_{j \mid i}=1$ then

$$
(r+\rho) U(j, i)=b(w(j, i))+\frac{\nu_{i} \pi_{j \mid i}}{\nu_{i} \pi_{j \mid i}+\lambda+r+\rho}(w(j, i)-b(w(j, i))),
$$

with $w(j, i)-b(w(j, i))>0$. On the other hand, if $\pi_{j \mid i}=0$ then, by Eq.(4), $(r+\rho) U(j, i)=b(w(j, i))$.

First one has to prove that $\pi_{n s \mid n e}=1$ and $\pi_{n s \mid e}=0$ imply $\phi_{n s}=0$. The result requires, from Eq.(5), $U(n s, e)<U(n s, n e)$. Given the preceding discussion, it suffices to prove that $w(n s, n e)>w(n s, e)$, which follows by using Eq.(13).

Second one has to prove the reverse that $\pi_{n s \mid n e}=1$ and $\phi_{n s}=0$ imply $\pi_{n s \mid e}=0$. One can proceed by contradiction by assuming $\pi_{n s \mid e}=1$. Use the discussion opening this proof to write the expressions for $U(n s, e)$ and $U(n s, n e)$. Using the Proposition 1 that $\nu_{e}>\nu_{n e}$ and, from Eq.(13), that $w(n s, e)>w(n e, n e)$, it follows that $U(n s, e)>U(n s, n e)$. From Eq.(5) this is a contradiction with the assumption that $\phi_{n s}=0$. Q.E.D.

When, like under the conditions of Proposition $2, \phi_{n s}=0$ then there are educated workers that perform jobs that do not require a qualification. This is a form of the phenomenon known as overeducation.

In general, one has to account for the possibility that two equilibria exist, one with $\phi_{n s}=0$ and the other with $\phi_{n s}=1$. In the case that $\phi_{n s}=1$ all educated workers, including those unskilled, participate in the educated segment. Graphically, in Figure 3 the equilibrium tightness in the educated segment $v_{e} / u_{e}$ is located to the left of the threshold $\left(v_{e} / u_{e}\right)^{*}$ and $\pi_{n s \mid e}=1$. If there exists another equilibrium with $\phi_{n s}=0$, it will have overeducation

\footnotetext{
${ }^{14}$ From Eq.(16) the sign of the difference between $U(n s, e)-U(n s, n e)$ in Eq.(5) depends on the sign of $w(n s, e)-w(n s, n e)$ which, by Eq.(13), is negative .
} 
and a skill composition where, relative to the equilibrium with $\phi_{n s}=1$, the skill of the labour force improves in the educated segment and worsens in the non-educated segment (see Eq.(1)). Graphically, in Figure 3 the equilibrium tightness in the educated segment $v_{e} / u_{e}$ is located to the right of the threshold $\left(v_{e} / u_{e}\right)^{*}$. The large tightness in the educated segment confirms the firm's decision to turn down non-skilled workers, $\pi_{n s \mid e}=0$ (see Eq. (14b) with (15)), and thus the career choice by non-skilled workers to leave the educated segment, $\phi_{n s}=0$ (see Proposition 2).

\section{Comparative statics}

For the purpose of this paper it will be important to identify the theoretical effects of exogenous factors on the endogenous variables of the model. This section discusses the consequences of a skill biased change in technology and the possible ensuing shifts in the skill composition of the labour force. A skill-biased shock widens the productivity gap between skilled and unskilled workers, so it will be represented as a rise in the skilled productivity $\eta_{s}$ and a reduction in non-skilled productivity $\eta_{n s}$ of equal size.

It will be supposed that the economy is initially in a steady-state equilibrium where unskilled yet educated workers do in effect participate in the educated segment, or $\phi_{n s}=1$, and consequently by Proposition 2 these workers can find employment in the educated segment, or $\pi_{n s \mid e}=1$. In other words, there is no overeducation since all educated workers are employed in the educated segment. Graphically, the equilibrium wage structure $w(j, i)$ and market tightness $v_{i} / u_{i}$ in each segment are determined as in Figures 2 and 3. As for the joint distribution of skills and education in the labor force $\mu(j, i)$, it will be assumed that the majority of educated agents are skilled and that the majority of non-educated workers are non-skilled. In the initial economy this means, by Eq. (1) and on account that $\phi_{n s}=1$, that the composition of skills of the labor force in each segment satisfies that $p_{s \mid e}>0.5$ and $p_{s \mid n e}<0.5$.

The observable variables that are the object of this paper are the unemployment rates for educated and non-educated workers respectively, residual inequality within each education group, and the wage premium. These can be calculated by aggregating appropriately the equilibrium outcomes of the model. Note that in the initial economy, the fact that there is no overeducation means that outcomes within a specific education group coincide with the outcomes within the corresponding segment. For a start, it is supposed that the SBTC does not change this situation and thus $\phi_{n s}$ remains 1 after the shock. Then the possible response of the career choice $\phi_{n s}$ will be considered. 


\subsection{Skill-biased change without overeducation}

Consider first the consequences of the SBTC in the educated segment. From Eq.(14) with (13) it is apparent that, given that $\pi_{s \mid e}=\pi_{n s \mid e}=1$ in the initial equilibrium, the impact of the larger $\eta_{s}$ and the lower $\eta_{n s}$ on vacancy profitability depends on the skill composition of the pool of unemployed searchers in this segment $z_{s \mid e}$. Note that according to Eq.(14c), in the initial economy this coincides with the skill composition of the labor force in this segment $p_{s \mid e}$, which has been assumed to exceed 0.5. With these conditions, it is clear that the SBTC increases the value of vacancy creation in the educated segment as represented in the left-hand side of Eq. (14) with (15) when $i=e$. Therefore the market tightness $v_{e} / u_{e}$ increases as the curve in Figure 3 shifts upwards. This will reduce the unemployment rate of educated workers. Wages as given in Eq.(13) increase for skilled jobs $w(s, e)$ but can go either way for unskilled jobs $w(n s, e)$. Graphically, the improvement in average productivity shifts upwards the job-creation curve $J C$ for both skilled and non-skilled workers, but the skill-specific changes in productivity shift the job-destruction curves $J D$ upwards for the skilled and downwards for the non skilled. As the gap between these two wage rates widens there is a rise in (residual) wage inequality within the group of educated workers.

Turning now to the non-educated segment, the lower $\eta_{n s}$ implies a lower profitability of vacancy creation in this segment. This follows from the fact that, in contrast with the educated segment, this is a skill-scarce segment in that $z_{s \mid n e}=p_{s \mid n e}<0.5$. Graphically, the curve in Figure 3 shifts downwards which causes tightness in this segment $v_{n e} / u_{n e}$ to fall. The inevitable consequence is a rise in the unemployment rate of the non-educated workers. The wages in unskilled jobs $w(n s, n e)$ fall but the wage in skilled jobs $w(s, n e)$ can go either way. Graphically, the loss in average productivity shifts downward the job-creation curve $J C$ for both skilled and non-skilled workers, but the skillspecific changes in productivity shift the job-destruction curves $J D$ upwards for the skilled and downwards for the non skilled. Like in the educated segment, as the gap between these two wage rates widens, there is a rise in residual wage inequality within the group of non-educated workers too.

As for wage differences across groups, the direct impact of the SBTC on relative productivity will tend to increase the average wage of the skill-abundant educated group relative to the skill-scarce non-educated group. The wage premium must increase as a consequence. Note that this direct effect will be reinforced by the induced shifts in tightness and unemployment in the two segments.

In sum, a SBTC that increases wage inequality, both within and across groups, produces an increase in unemployment among non-educated workers but a fall 
in unemployment within the educated group. The latter is at odds with the generalized rise in unemployment in the US over the period 1970-1990.

\subsection{Skill-biased change and overeducation}

A skill-biased technical change can be large enough to change the initial policy of firms in the educated segment to hire non-skilled workers, $\pi_{n s \mid e}=1$. The relative reduction in the productivity of non-skilled workers $\eta_{n s}$ can, according to Eq.(14b) with (15), render them unprofitable in this segment and lead firms in this segment to refuse filling vacancies with such type of workers, or $\pi_{n s \mid e}=0$. Proposition 2 then implies that unskilled workers will turn to the non-educated segment, or $\phi_{n s}=0$, and overeducation arises. Note that, since it has to be assumed that $\eta_{n s}-b\left(\eta_{n s}\right)>0$ for the non-educated firms to hire non-skilled workers, overeducation can only happen if the cost of creating a job $c_{k}$ is positive.

In these circumstances, it is instructive to break down the consequences of a SBTC into a direct effect - similar to the one operating without overeducation and an unchanged $\pi_{n s \mid e}=1$ - and an indirect effect which operates through the induced shifts in the skill composition of the labor force in the two segments.

Consider first the direct effect of the SBTC. In the educated segment, the curve in Figure 3, summarizing the equilibrium Eq.(14) and (15), shifts up far enough to determine and equilibrium to the right of the discontinuity which is the region where $\pi_{n s \mid e}=0$. Note also that the threshold $\left(v_{e} / u_{e}\right)^{*}$ has shifted to the left. The rise in tightness also seen without overeducation follows. In terms of Figure 2, like in the case without overeducation, the JC curves move upwards, and the JD curves move up and down for the skilled and unskilled matches respectively, so a wider wage dispersion within the educated segment follows. Note, however, that since $\pi_{n s \mid e}=0$ the JC curve for the nonskilled workers in Figure 2 ceases to exist. ${ }^{15}$ In the non-educated segment, the direct effect of the SBTC follows along the same lines as in the case without overeducation. The fall in average productivity shifts downwards the curve in Figure 3 leading to a lower market tightness $v_{n e} / u_{n e}{ }^{16}$ The dispersion of wages paid in this segment also widens following the shifts in the JC and JD curves in Figure 2 which parallel those in the case without overeducation.

Besides these direct effects, the rise in overeducation causes indirect effects operating through the associated shifts in the composition of the labour force

\footnotetext{
${ }^{15}$ Still the JD curve shifts downwards and determines the notional wage for the non-skilled workers $w(n s, e)$.

16 This segment will always remain in the region to the left of the threshold $\left(v_{n e} / u_{n e}\right)^{*}$ and thus $\pi_{n s \mid n e}=1$.
} 
in the two segments, $p_{s \mid e}$ and $p_{s \mid n e}$. In effect, that $\phi_{n s}$ goes from 1 to 0 means that the subset of educated workers who are non-skilled quit the educated segment and move into the non-educated segment. As it is clear from Eq.(1), the skill composition of labour then improves in the educated segment but declines in the non-educated segment. The profitability of vacancy creation further increases in the educated segment and declines in the non-educated segment. This reinforces the shifts of the corresponding curves in Figure 3 and the job-creation curves $J C$ in Figure 2 in the two segments and, therefore, the changes in the corresponding equilibrium market tightness and wages.

In sum, a SBTC brings about a widening gap between skilled and non-skilled wages in the two segments, a rise in tightness in the educated segment, and a fall in the non-educated segment. Following up the preceding discussion, this continues to be true if the SBTC also causes overeducation which, in fact, tends to reinforce those responses. As for aggregate measures of unemployment and earnings by education group, the emergence of overeducation might be more significant since it leads to the existence of a fraction of the educated labor force whose wages and unemployment will come to be determined within the high-unemployment (and low-wage) segment of non-educated jobs. It is thus that, when accompanied by overeducation, a SBTC might account for the rise in the educated unemployment rate characteristic of the US experience over the period 1970-1990. Remember from section 4.1 that, absent overeducation, a SBTC is bound to fail on that front.

\section{Calibration}

One model's period is assumed to correspond to one quarter. The parameters to be determined are: $b_{1}, r, \rho, \lambda, \theta, \beta, \eta_{s}, \eta_{n s}, b_{0}, c_{R}, m_{0}, c_{k}$, and the skill distribution $\mu(j, i)$ for $i=e$, ne and $j=s, n s$. Six of these parameters can be set directly. The choice of $b_{1}$ is consistent with an unemployment benefit (UI) replacement rate of $20 \%$ from OECD (1997). Stewart (2002) finds on March CPS data an average separations rate for males in 1970 of $23 \%$. This includes employment-to-unemployment and employment-to-employment transitions. This is approximately $6 \%$ per quarter, the number used for $\lambda$ in the calibration. A 5\% annual interest rate in Cooley and Prescott (1995) implies the value 0.013 for $r$. A life-expectancy in the labor market of 45 years implies $\rho=1 /(45 \times 4)$. The matching elasticity $\theta$ is set following the estimate in Blanchard and Diamond (1990). Since the calibration procedure will target figures for unemployment rates, one can argue that the choice of either $m_{0}$ or $c_{R}$ is a normalization and can fix $m_{0}$. The start-up cost $c_{k}$ is chosen small enough so that in 1970 there is a regime with low overeducation or $\phi_{n s}=1$ on account of the evidence in Pryor and Schaffer (1997) that 1970 precedes the rise in overeducation. 
To determine the remaining parameters outcomes are restricted to be consistent with targets for the key endogenous variables corresponding to the year 1970. There are two blocks to this task. One block of the calibration procedure consists of matching the four targets for the wage premium, the unemployment rates of educated and non-educated workers, and the value of the recruiting cost as a proportion of wage income by choice of the four parameters $\eta_{s}, b_{0}$, $\beta$, and $c_{R}$. It is assumed that $\eta_{s}+\eta_{n s}=3$, so $\eta_{s}$ determines $\eta_{n s}$ directly and changes in $\eta_{s}$ can be regarded as skill-biased changes in technology. The targets for the wage premium and unemployment are taken from the 1970 data of Table 1. Concerning hiring costs, Hamermesh (1993) estimated that average hiring costs represent about 2 per cent of the wage bill.

Table 2. Calibration

\begin{tabular}{llll}
\hline parameter & value & target to match & source \\
\hline$b_{1}$ & 0.2 & UI replacement 20\% & OECD (1997) \\
$r$ & 0.013 & annual interest 5\% & Cooley et al. (1995) \\
$\rho$ & 0.0055 & working life 45 years & \\
$\lambda$ & 0.06 & annual separation rate 25\% & Stewart (2002) \\
$\theta$ & 0.5 & matching elast. 0.5 & Blanchard et al. (1990) \\
$m_{0}$ & 1 & normalize to unity & \\
$c_{k}$ & 0.05 & low overeduc. $\phi_{n s}=1$ & Pryor et al. (1997) \\
\hline$\mu(n s, e)$ & 0.085 & college partic. 25\% & US Census Bureau (1995) \\
$\mu(s, e)$ & 0.165 & residual ineq. diff. 0.06 & Gould (2002) \\
$\mu(s, n e)$ & 0.035 & & \\
$\mu(n s, n e)$ & 0.715 & normalize mass 1 & \\
\hline$\eta_{s}=3-\eta_{n s}$ & 1.915 & wage premium 1.44 & Murphy et al. (1992) \\
$b_{0}$ & 0.770 & unemp. educ. 1.1\% & US Census Bureau (1995) \\
$\beta$ & 0.140 & unemp. non-educ. 2.4\% & US Census Bureau (1995) \\
$c_{R}$ & 0.10 & recruiting costs 2\% & Hamermesh (1993) \\
\hline
\end{tabular}

In the other block, the parameters $\mu(j, i)$ 's are calibrated to match the targets of educational attainment and measures of inequality within defined occupational categories that can be associated with the two segments in the model. The education target can be written in terms of these parameters as $e d u c=\mu(s, e)+\mu(n s, e)$. Residual variances depend on the implied $p_{s \mid i}$ 's which can be written $p_{s \mid e}=\mu(s, e) / e d u c$ and $p_{s \mid n e}=\mu(s, n e) /(1-e d u c)$. These relations, along with the normalization $\sum_{i, j} \mu(j, i)=1$, pin down the distribution parameters. The target for education is the 1970 figure for college participation of the male labor force aged 25, calculated as the percentage with four or more years of college divided by the percentage with four or more years of high school (see US Census Bureau, 1995, Table 629). Concerning inequality 
within job categories, Gould (2002, Fig. 1b) reports the variance of the OLS log-wage residuals from uniform March CPS data for white males, after controlling for years of schooling, experience, region of residence, marital status, and living in a standard metropolitan statistical area. These measures are provided for various years within three different occupation groups: professional sector, service sector, and blue collar sector. In the calibration, it is assumed that the educated segment and the non-educated segment correspond to the professional sector and the blue-collar sector respectively. For 1970 the residual variance of log wages for the professional and blue-collar sectors are 0.18 and 0.12 respectively. The target to match will be the 0.06 differential residual variance of educated over non-educated jobs in $1970 .{ }^{17}$ Since the differential in residual variance is targeted, rather than the two absolute values there is one degree of freedom. The choice made here implies that the skill composition of the two segments is given by $p_{s \mid e}=0.660$ and $p_{s \mid n e}=0.0467$. Table 2 displays the benchmark calibration and summarizes the procedure. All targets set out are matched exactly, with the educated and non-educated residual variances being 0.07 and 0.01 .

\section{$6 \quad$ Numerical exercises}

This section studies the response of unemployment rates for educated and non-educated workers, residual inequality within each education group, and the wage premium to shifts in various exogenous factors within the model. ${ }^{18}$ The factors considered will include a skill-biased change in technology, a shock to the level of employment frictions, and changes in the distribution of skills in the labor force. This section proceeds in several parts. In the first part the purpose is to explain the 1970-1990 changes in the U.S. labor market reported in Table 1 . The primary explanatory factor considered will be a skillbiased change in technology, or SBTC. An additional shock to the level of employment frictions will also be considered. In the second, the quantitative model will be used to interpret the 1970-1980 developments where changes in the distribution of the labor force will play a role.

\footnotetext{
${ }^{17}$ In the model one can calculate the variance within a segment $i$ as $(\log w(s, i)-$ $\log w(n s, i))^{2} p_{s \mid i}\left(1-p_{s \mid i}\right)$ where $p_{s \mid i}$ is the share of skilled in the segment.

${ }^{18}$ To trace the response of these variables it is necessary first to measure them more precisely in terms of the variables of the model. This is done in the Appendix.
} 


\subsection{The role of a SBTC in the period 1970-1990}

The skill-biased shock can be represented by a rise in the productivity of the skilled workers, $\eta_{s}$, and a corresponding decline in the productivity of the nonskilled workers, $\eta_{n s}=3-\eta_{s} .{ }^{19}$ An employment shock can be represented by a reduction in $m_{0}$. This section reports the effect of this type of shock on the calibrated benchmark economy. The main results of the experiments conducted are contained in Table 3. ${ }^{20}$ Each row shows first the value of the parameters $\eta_{s}$ and $m_{0}$, and the endogenous career choice $\phi_{n s}$ which characterizes the presence or absence of overeducation. The rest of entries on each row contain the key observable variables: the wage premium $w p$, the unemployment rate of the educated $u n_{e}$, the unemployment rate of the non-educated $u n_{n e}$, and the residual inequality for the educated, $\mathrm{res}_{e}$, and the non-educated, $r e s_{n e}$. The first row shows the figures corresponding to the benchmark 1970 equilibrium. The second row reproduces the 1990 data on the observable variables in order to facilitate the comparison with the implications of the numerical experiments.

Table 3. Skill biased technical change and the 1970-1990 period

\begin{tabular}{ccccccccc}
\hline \hline & \multicolumn{3}{c}{ parameters } & overeducation & \multicolumn{5}{c}{ observable variables } \\
\hline & $\eta_{s}$ & $m_{0}$ & $\phi_{n s}$ & $w p$ & $u n_{e}$ & $u_{n e}$ & rese $_{e}$ & res ne \\
$(1)$ & 1.915 & 1.000 & 1 & 1.440 & 0.011 & 0.024 & 0.065 & 0.011 \\
$(2)$ & & & & 1.580 & 0.021 & 0.053 & & \\
\hline$(3)$ & 1.980 & 1.000 & 1 & 1.533 & 0.011 & 0.032 & 0.089 & 0.015 \\
$(4)$ & & & 0 & 1.545 & 0.017 & 0.033 & 0.092 & 0.014 \\
$(5)$ & 1.990 & 1.000 & 0 & 1.561 & 0.018 & 0.035 & 0.096 & 0.015 \\
$(6)$ & 2.010 & 1.000 & 0 & 1.594 & 0.020 & 0.041 & 0.104 & 0.015 \\
\hline$(7)$ & 2.010 & 0.800 & 0 & 1.591 & 0.024 & 0.051 & 0.101 & 0.014 \\
\hline
\end{tabular}

The first experiment focuses on the skill-biased shock only. Rows 3 to 6 show the changes as $\eta_{s}$ is increased. The third row corresponds to an equilibrium where, like in the initial benchmark, there is no overeducation. The wage premium, the measures of residual inequality, and the unemployment rate for the non-educated have increased. However, the unemployment rate of the educated labor force fails to increase. These conclusions conform the analysis

\footnotetext{
${ }^{19}$ Equivalently, one might postulate a widening gap with positive growth in both productivities while the economy-wide parameters increase at an average rate that must exceed the rise in non-skilled productivity.

${ }^{20}$ Alternatively and to the same effect, this type of shock could be represented by an increase in the separation rate $\lambda$. See Cuadras-Morató and Mateos-Planas (2006) for a discussion of this point.
} 
presented above in section 4.1. Now for the same parameters, this economy has another equilibrium with overeducation and the fourth row shows the outcomes associated with it. The key feature of this equilibrium is the increase in the educated unemployment rate which follows from overeducation in the way discussed in section 4.2 above. The comparison of the third and fourth rows reveals that the increase in overeducation may on its own account for an increase in the educated unemployment rate as a consequence of a SBTC.

The fifth and sixth rows display the outcomes associated with larger SBTC's. The equilibrium is unique and features overeducation in that $\phi_{n s}=0$. Specifically, the $\eta_{s}$ in the sixth row has been chosen to nearly match the observed wage premium in 1990. We observe that, against the observed 1970-1990 changes, the SBTC so measured is able to produce nearly all of the rise in the educated unemployment rate and about sixty per cent of the rise in the non-educated unemployment rate, as well as a sizeable upward shifts in residual inequality within the two education groups. Thus the theory advanced early that a SBTC can account for the 1970-1990 changes in all the variables also fares well under the rigour of a quantitative exercise.

Although the SBTC accounts for much of the observed changes over the period 1970-1990, it still leaves unexplained a sizeable portion of the rise in the non-educated unemployment rate. This suggests some additional exogenous factor must have been at work. For example, one could think of an increase in labour market frictions that can be characterized by a lower efficiency of the matching process. The seventh row of Table 3 considers a reduction of the matching parameter $m_{0}$ alongside the SBTC characterized by an increase in $\eta_{s}-\eta_{n s}$. The fall in $m_{0}$ is tuned to nearly match the rise in non-educated unemployment. Although now the educated unemployment rate exceeds the 1990 observation, the combined effect of a SBTC and a mismatch shock provides a fairly complete account of the 1970-1990 facts.

Note that the rise of overeducation is key to this result and that it can only happen as long as a positive fixed start-up cost $c_{k}>0$ is assumed. In CuadrasMorató and Mateos-Planas (2006)the start-up cost is instead zero and overeducation does not respond to the SBTC. In that case, with a given distribution of skills $\mu$ in the way assumed in the present paper, a SBTC invariably fails to cause a realistic increase in the educated unemployment rate, and this is true even if it is accompanied by a suitable shock to employment conditions (e.g., $\lambda$ or $\left.m_{0}\right)$. 


\subsection{The 1970-1980 period and the skill distribution}

The wage premium declined markedly between 1970 and 1980 - from the initial 1.44 in Table 1 down to 1.37 - before launching on the subsequent sharper increases. How can this model reconcile this observation with the presence of SBTC driving up unemployment rates? It will be shown that a shift in the distribution of skills could account for this early decline. More specifically, the substantial increase in college participation or the entry of the baby boom generation into the labor force might have led to a deterioration of the average quality of the college workers, $\mu(s, e)$ up to, roughly, 1980 . The evidence of declining GRE scores clearly supports this view. Figure 4 shows that the growth in college participation was particularly rapid in the period to the early 80's. Figure 4 also displays average GRE scores of verbal and numerical competence for college graduates, and shows a clear decline during the 70's. This trend is reversed past 1980 as, it seems plausible to conjecture, the education system adjusts to bring the skill composition $\mu(s, e)$ close to its initial 'natural' level by 1990 .

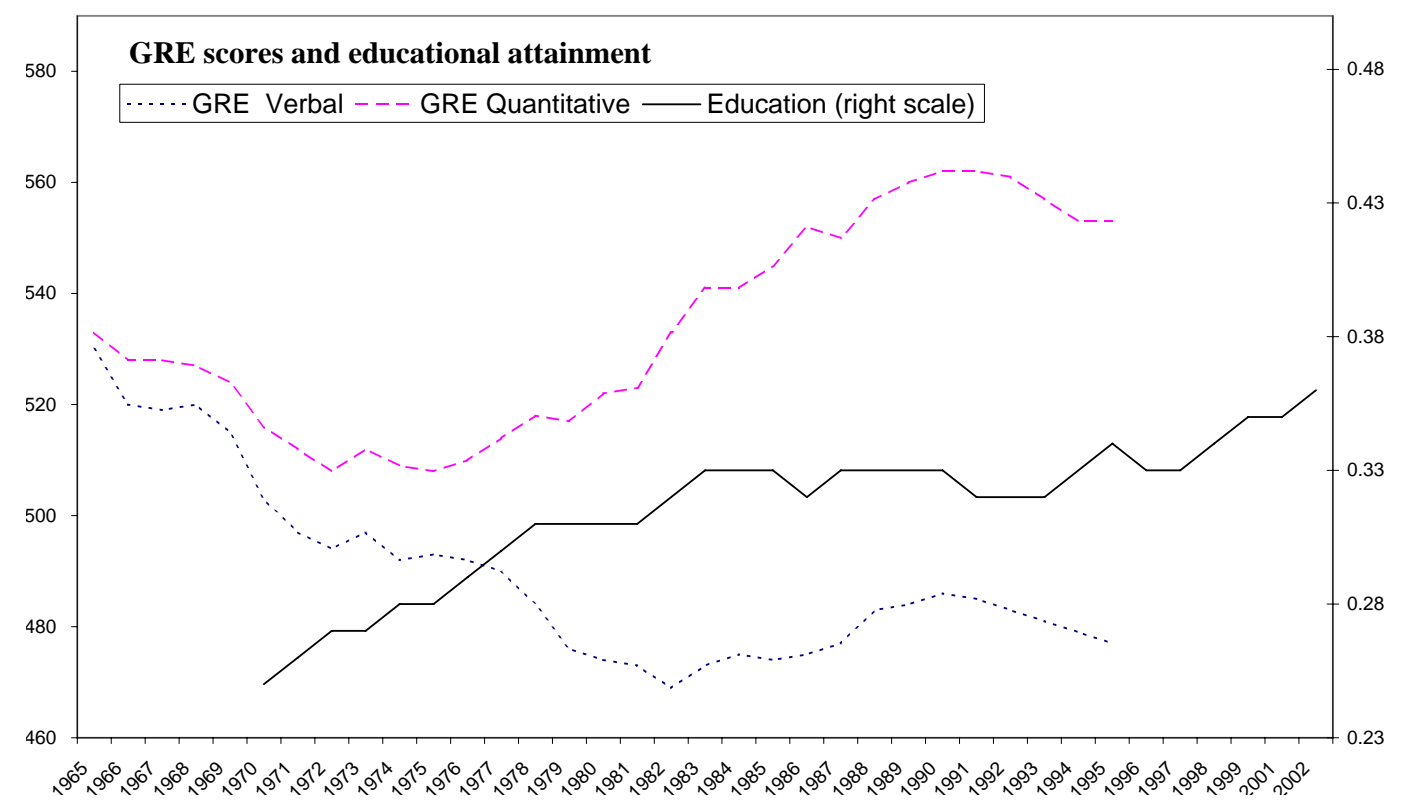

Figure 4. Educational attainment 1970-2002 as the percentage of male civilian force 25 to 64 years of age with a high school diploma who are college graduates. Source: Women in the Labor Force: A Databook, US Bureau of Labor Statistics, 2004. Graduate Record Examination (GRE) average scores of quantitative and verbal competence, 1965-1995. Source: Digest of education statistics, tables and figures 1996, National Center for Education Statistics (http://nces.ed.gov).

This section explores the implications of these developments within the model. Table 4 shows the results of some calculations. Each row corresponds to a specific setting for the exogenous parameters associated with the SBTC, $\eta_{s}$, and 
the skills distribution, $\mu(s, e)$. In this experiments, a change in $\mu(s, e)$ is always accompanied by an adjustment of $\mu(n s, e)$ so that $\mu(s, e)+\mu(n s, e)$ remains constant. The first row of Table 4 reproduces the calibrated 1970 benchmark. The other rows from (2) to (6) demonstrate that, when accompanied with a lower $\mu(s, e)$, the SBTC can produce general rises in the two unemployment rates, and the two measures of residual inequality, at the same time as the wage premium declines. The SBTC still must be large enough to produce a switch in career choice $\phi_{n s}$ towards overeducation which accounts for most of the increase in the educated unemployment rate. Specifically, the fifth and sixth rows in Table 4 report outcomes which nearly match the observed 1.37 wage premium in 1980 .

Table 4. SBTC, skills distribution, and the $1970-1980$ period

\begin{tabular}{ccccccccc}
\hline \hline & \multicolumn{3}{c}{ parameters } & overeducation & \multicolumn{5}{c}{ observable variables } \\
\hline & $\eta_{s}$ & $\mu(s, e)$ & $\phi_{n s}$ & $w p$ & $u n_{e}$ & $u n_{n e}$ & res $_{e}$ & res \\
$(1)$ & 1.915 & 0.165 & 1 & 1.440 & 0.011 & 0.024 & 0.065 & 0.011 \\
\hline$(2)$ & 1.990 & 0.130 & 0 & 1.436 & 0.022 & 0.036 & 0.107 & 0.015 \\
$(3)$ & 1.990 & 0.120 & 0 & 1.401 & 0.023 & 0.036 & 0.108 & 0.015 \\
$(4)$ & 2.000 & 0.120 & 0 & 1.413 & 0.024 & 0.038 & 0.112 & 0.015 \\
$(5)$ & 1.990 & 0.110 & 0 & 1.365 & 0.024 & 0.036 & 0.106 & 0.015 \\
$(6)$ & 2.000 & 0.110 & 0 & 1.376 & 0.025 & 0.038 & 0.111 & 0.015 \\
\hline
\end{tabular}

Table 5. SBTC, skills, and mismatch over 1970-1980

\begin{tabular}{cccccccccc}
\hline \hline & \multicolumn{3}{c}{ parameters } & overeduc & \multicolumn{5}{c}{ observable variables } \\
\hline & $\eta_{s}$ & $\mu(s, e)$ & $m_{0}$ & $\phi_{n s}$ & $w p$ & $u n_{e}$ & $u n_{n e}$ & res & res \\
$(1)$ & 1.915 & 0.165 & 1.00 & 1 & 1.440 & 0.011 & 0.024 & 0.065 & 0.011 \\
\hline$(2)$ & 1.915 & 0.140 & 0.80 & 1 & 1.364 & 0.015 & 0.031 & 0.069 & 0.011 \\
$(3)$ & 1.980 & 0.120 & 0.80 & 1 & 1.370 & 0.016 & 0.040 & 0.094 & 0.014 \\
$(4)$ & 1.990 & 0.110 & 0.80 & 1 & 1.344 & 0.017 & 0.042 & 0.096 & 0.014 \\
$(5)$ & & & & 0 & 1.364 & 0.030 & 0.045 & 0.105 & 0.014 \\
$(6)$ & 2.000 & 0.110 & 0.80 & 1 & 1.353 & 0.017 & 0.045 & 0.101 & 0.014 \\
$(7)$ & & & & 0 & 1.375 & 0.032 & 0.048 & 0.109 & 0.014 \\
\hline
\end{tabular}

Table 5 reports experiments where, in addition to the SBTC and the change in the distribution of skills, there is a fall in the efficiency of matching. The first row corresponds again to the calibrated benchmark. The other entries consider combinations of $\eta_{s}, \mu(s, e)$ and $m_{0}$ that approximately match the 1980 wage premium of 1.37. The second row shows that without SBTC, a lower matching efficiency and skill of the educated cannot effect the increase in residual inequality among the non-educated, and overeducation cannot arise. The other 
variables move in the right direction although by substantially smaller amounts than in the case with SBTC and without the mismatch shock seen above in rows 5 and 6 of Table 4 . It is only when a SBTC is added that there is a rise in residual inequality for the non-educated and, overall, changes are quantitatively more in line with observations. This is particularly true when, as it is the case in the third row, the SBTC is not big enough to cause overeducation. If there is overeducation instead the model implies too big an increase in the educated unemployment rate.

In sum, a deterioration of the skills in the educated labor force is necessary to account for the 1970-1980 drop in the wage premium. A SBTC is also needed to account for residual inequality in this period. If the SBTC causes overeducation, then the addition of an extra shock in the form of a reduction in matching efficiency overestimates the rise in educated unemployment. With a large enough decline in matching efficiency, the model delivers unemployment outcomes comparable with the data for 1970-1980 only if the SBTC does not cause overeducation to rise. Since the direct evidence of overeducation is quite compelling, this analysis suggests that the SBTC can account for most of the changes in unemployment over the 1970-1980 subperiod.

\section{Conclusion}

This paper extends the standard search-matching model by introducing the possibility of overeducation in a segmented labor market where education and skill are not equivalent attributes of a worker. Equilibrium properties of the model are characterized. The model is used to study the response of unemployment and wage inequality to a skill-biased change.

The SBTC leads to increases in the wage premium, in residual inequality, and in the unemployment rates of both educated and non-educated workers. The endogenous increase in overeducation plays an essential part as it explains the consequences of the shock for the unemployment rate of educated workers. With overeducation, there are educated workers participating in the high-unemployment segment of jobs that do not require a degree. Overeducation occurs among the educated workers who have a low ability since, in the presence of a positive startup cost, the SBTC renders those workers unprofitable to firms in the educated segment. A calibrated setting is used to study quantitatively a skill-biased change in technology as the cause of the changes in education-specific unemployment rates and the wage premium in the U.S. economy between 1970 and 1990. This shock alone can account for most of the observed changes in these three variables, while being also consistent with the evidence of a wider residual dispersion in wages and a higher degree of overeducation. On the other hand, a temporary drop in the aver- 
age skill quality within the educated group can reconcile the SBTC with the falling wage premium and soaring unemployment rates in the initial period 1970-1980, without need of invoking other explanations such as a decline in the efficiency of matching. This change in the skill composition can be motivated by the rapid growth in the numbers of college graduates and supported by some direct evidence from performance scores.

This paper has limitations which hint at interesting extensions. Changes in the distribution of skills and education status in the labor force have been treated as exogenous, but education choices could be made endogenous. The model cannot match observed levels of residual inequality and the implications on this dimension can only be assessed qualitatively. The analysis centers around steady-state outcomes which may have limitations, specially in reference to the subperiod 1970-1980.

\section{References}

Acemoglu, D., "Changes in unemployment and wage inequality: an alternative theory and evidence," American Economic Review 89 (1999), 1259-1278.

Autor, D., L. Katz, and A. B. Krueger, "Computing inequality: have computers changed the labor market?," Quarterly Journal of Economics 113 (1998), 1169-1215.

Albrecht, J. and S. Vroman, "A matching model with endogenous skill requirements," International Economic Review 43 (2002), 283-305.

Blanchard, O. J. and P. A. Diamond, "The Beveridge curve," Brookings Papers on Economic Activity 2 (1989), 85-143.

Blanchard, O. J., and P. A. Diamond, "The cyclical behavior of the gross flows of US workers," Brooking Papers on Economic Activity 2 (1990), 85-143.

Bleakey, H. and J. C. Fuhrer, "Shifts in the Beveridge curve, job matching, and labor market dynamics," New England Economic Review Sept./Oct. (1997), 3-19.

Card, D. and J. E. Di Nardo, "Skill-biased technological change and rising wage inequality: some problems and puzzles," Journal of Labor Economics 20 (2002), 733-783.

Cooley, T. F. and E. Prescott, "Economic growth and business cycles," in T. Cooley, ed., Frontiers of Business Cycle Research (Princeton University Press, 1995), 1-38.

Cuadras-Morató, X. and X. Mateos-Planas, "Skill bias and employment fric- 
tions in the US labor market 1970-1990," International Economic Review, forthcoming (2006).

Gould, E. D., "Rising wage inequality, comparative Advantage, and the growing importance of general skills in the United States," Journal of Labor Economics 21 (2002), 105-147.

Hamermesh, D., Labor Demand, (Princeton University Press, 1993).

Heathcote, J., K. Storesletten, and G. L. Violante, "The macroeconomic implications of rising wage inequality in the United States," mimeo NYU, August (2004).

Juhn, Ch., K. Murphy, K., B. Pierce, "Wage inequality and the rise in the return to skill," Journal of Political Economy 101 (1993), 410-442.

Katz, L. F. and K. M. Murphy, "Changes in Relative Wages, 1963-1987: Supply and Demand Factors," Quarterly Journal of Economics 107 (1992), 35-78.

Krusell, P., L. Ohanian, V. Rios-Rull, and G. L. Violante, "Capital-skill complementarity and inequality: a macroeconomic analysis," Econometrica 68 (2000), 1029-1053.

Lemieux, T., "Increasing residual wage inequality: composition effects, noisy data, or rising demand for skill?," manuscript, University of British Columbia (2004).

Moore, M. P. a,d P. Ranjan, "Globalisation vs skill-biased technological change: implications for unemployment and wage inequality," Economic Journal 115 (2005), 391-422.

Mortensen, D. T. and C. A. Pissarides, "Job creation and job destruction in the theory of unemployment," Review of Economic Studies 61 (1994), 397-415.

Mortensen, D. T. and C. A. Pissarides, "Unemployment responses to skillbiased shocks: the role of labor market policy," Economic Journal 109 (1999), 242-265.

Murphy, K. M. and F. Welch, "The structure of wages," Quarterly Journal of Economics 107 (1992), 285-325.

OECD, Implementing the OECD Jobs Strategy, (Paris:OECD, 1997).

Pryor, F. L. and D. Schaffer, "Wages and the university educated: a paradox resolved," Monthly Labor Review July (1997), 3-18.

Saint-Paul, G., "Are the unemployed unemployable?," European Economic 
Review 40 (1996), 1501-1519.

Shi, S., "A directed search model of inequality with heterogeneous skills and skill-biased technology," Review of Economic Studies 69 (2002), 467-491.

Stewart, J., "Recent trends in job stability and job security: evidence from the March CPS," U.S. Bureau of Labor Statistics, Working Paper 356, March 2002.

US Census Bureau, Statistical Abstracts of the United States, (U.S. Census Bureau, 1995).

Violante, G. L., "Technological acceleration, skill transferability and the rise of residual inequality," Quarterly Journal of Economics 117(1) (2002), 297-338.

Wolff, E., "Technology and the demand for skills", in L. Borghans and A. de Grip The Overeducated Worker? (The Economics of Skill Utilization), Edward Elgar Publishers (2000).

Wong, L. Y., "Can the Mortensen-Pissarides model with productivity changes explain U.S. wage inequality?," Journal of Labor Economics 21 (2003), 70-105.

\section{A Measurement of observable variables}

The unemployment rate for the educated workers $u n_{e}$ averages the unemployment probabilities in the two segments where they can participate. In a steady-state it reads:

$$
\begin{aligned}
u n_{e}= & \frac{\lambda+\rho}{\lambda+\rho+\pi_{s \mid e} \nu\left(v_{e} / u_{e}\right)} \frac{\mu(s, e)}{\mu(s, e)+\mu(n s, e)}+ \\
& \frac{\lambda+\rho}{\lambda+\rho+\left[\phi_{n s} \pi_{s \mid e} \nu\left(v_{e} / u_{e}\right)+\left(1-\phi_{n s}\right) \pi_{n s \mid e} \nu\left(v_{n e} / u_{n e}\right)\right]} \frac{\mu(n s, e)}{\mu(s, e)+\mu(n s, e)}
\end{aligned}
$$

If all the educated workers participate in the educated segment then $\phi_{n s}=1$ and their unemployment rate is fully determined by the tightness in that segment. Otherwise, $\phi_{n s}=0$ and the tightness in the non-educated segment and the relative number of non-skilled educated workers who search in the non-educated segment will also matter. Note that since, by Proposition 2, tightness is lower in the non-educated segment, this form of over-education will tend to increase the overall unemployment rate of the educated labor force.

As for the non-educated workers, only the non-educated segment is available 
and the corresponding unemployment rate can be written as

$$
\begin{aligned}
u n_{n e}= & \frac{\lambda+\rho}{\lambda+\rho+\pi_{s \mid n e} \nu\left(v_{n e} / u_{n e}\right)} \frac{\mu(s, n e)}{\mu(s, n e)+\mu(n s, n e)}+ \\
& \frac{\lambda+\rho}{\lambda+\rho+\pi_{n s \mid n e} \nu\left(v_{n e} / u_{n e}\right)} \frac{\mu(n s, n e)}{\mu(s, n e)+\mu(n s, n e)}
\end{aligned}
$$

In the case we will always consider that $\pi_{s \mid n e}=\pi_{n s \mid n e}=1$, the non-educated unemployment rate is fully determined by market tightness in the non-educated segment $v_{n e} / u_{n e}$.

Turning now to wages, the proportion of skilled among the educated employed workers is:

$$
\begin{aligned}
s_{e}= & \mu(s, e)\left(1-\frac{\lambda+\rho}{\nu_{e}+\lambda+\rho}\right) \\
& {\left[\mu(s, e)\left(1-\frac{\lambda+\rho}{\nu_{e}+\lambda+\rho}\right)+\mu(n s, e)\left(1-\frac{\lambda+\rho}{\phi_{n s} \nu_{e}+\left(1-\phi_{n s}\right) \nu_{e}+\lambda+\rho}\right)\right]^{-1} }
\end{aligned}
$$

the proportion of skilled among the educated employed workers is $s_{n e}=$ $\mu(s, n e)[\mu(s, n e)+\mu(n s, n e)]^{-1}$. Denote by $\tilde{w}(j, i)$ the wage earnt by a worker of skill $j$ and education $i$. Naturally, $\tilde{w}(j, i)=w(j, i)$ except for $\tilde{w}(n s, e)=$ $\phi_{n s} w(n s, e)+\left(1-\phi_{n s}\right) w(n s, n e)$. The residual variances are $r e s_{i}=(\log \tilde{w}(s, i)-$ $\log \tilde{w}(n s, i))^{2} s_{e}\left(1-s_{e}\right)$ for $i=e, n e$. The average wage of each education group $i$ are similarly calculated using $s_{i}$ to weight the wages $\tilde{w}(j, i)$. 